\title{
Building an effective training continuum in surgery: Developing a safe practitioner
}

\author{
Dujeepa D. Samarasekera1, MBBS (Colombo), MHPE (Maastricht) \\ Matthew C.E. Gwee ${ }^{2}$, MHPE (UNSW, Sydney), PhD
}

\begin{abstract}
1 Deputy Head, Medical Education Unit, Dean's Office, Yong Loo Lin School of Medicine, National University of Singapore. Honorary Professor, Semey State Medical University, Kazakhstan.

External Evaluator, Centre for Medical and Health Professional Education, University of Auckland, New Zealand.

2 Professorial Fellow and Chairman International Programmes, Medical Education Unit, Dean's Office, Yong Loo Lin School of Medicine, National University of Singapore.
\end{abstract}

\section{ABSTRACT}

Medical education has initiated major paradigm shifts in the last few decades aimed primarily at meeting the challenges of medical practice in the 21st century and also because of patient safety concerns. It is imperative that the design of a curriculum appropriate for surgical trainees in this new millennium must ensure a continuum of learning from undergraduate to postgraduate education and training. Educational leaders and team members responsible for planning and implementation of any curriculum reform should apply the principles of Best Evidence Medical Education (BEME) in the decisionmaking process in order to optimise the educational process and results. It is best to adopt a result oriented course design in developing and planning a surgical training programme which would equip the surgeon with the requisite professional competencies for practice in the 21st century.

Key words: Curriculum design; Curriculum development; Clinical Competencies; Outcome Based Education; Entrustable Professional Activities; Milestones; Student Assessment.

\section{"Today's Practice, Yesterday's Legacy, Tomorrow's Challenges" [1]}

Medical education has initiated major paradigm shifts over the last few decades. Contemporary medical curricula are designed to meet the challenges of future practice and patient safety concerns as well as to maintain and achieve the professional standards and guidelines stipulated by the accreditation bodies. The ultimate aim of the changes made in medical curricula is to improve the delivery of quality patient care by medical practitioners [2].

\section{Nurturing the interdependence of education and practice}

A medical curriculum is not independent of the practice environment. Both undergraduate medical education and postgraduate specialist training require patients (hospital inpatients, ambulatory clinic patients, patients from community settings) as well as various healthcare professionals to teach or facilitate student learning. However, student learning and the educational preparation for safe and effective future prac-

Correspondence: Dujeepa D. Samarasekera, Dean's Office School of Medicine, 1E, Kent Ridge Road

NUHS Tower Block, Level 11, Singapore 119228

E-mail: dujeepa_samarasekera@nuhs.edu.sg

Tele: +6565163760 Fax: +6568721454 tice will largely depend on how these elements are incorporated into the curriculum and the way it is operationalised. Much of the success will depend on a close alignment of student/trainee learning with the health needs of the patients and communities ie. the curricula has to ensure a close match with the patient and population needs. The contemporary curricular designs are aimed at achieving this symbiosis ie. medical education improving clinical services which in turn serve to improve and refine medical education [3].

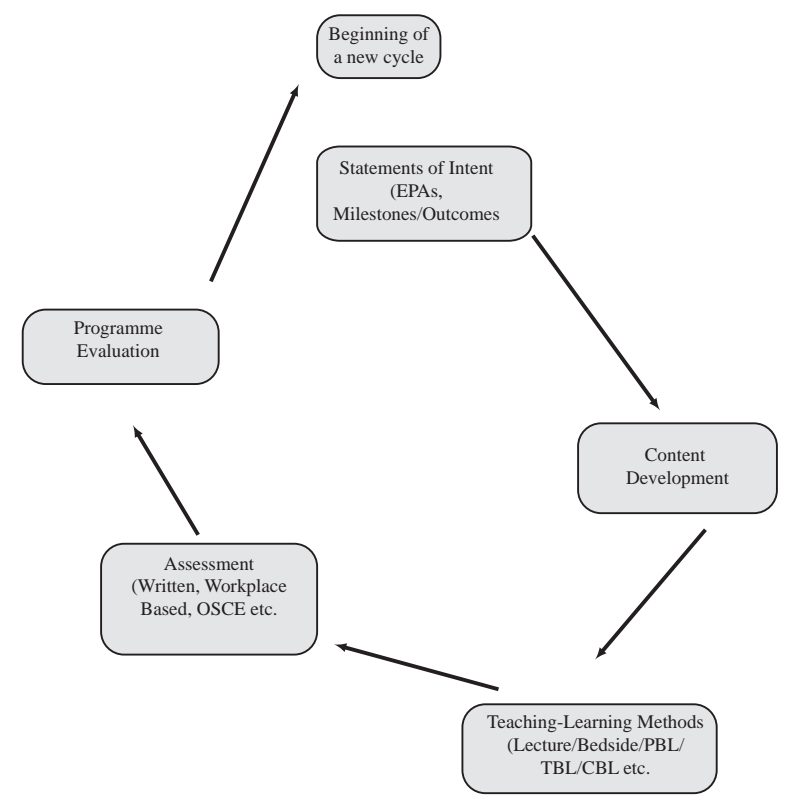

Figure 1: Highlighting the key elements of Outcomes Based Design 
Building an effective training continuum in surgery: Developing a safe practitioner

\section{Using Outcome Based Education/Course Design (OBE)}

One of the major paradigm shifts in medical curricular design in the early 1990s was the move from an input based model to an Outcome-Based model [4]. Outcomebased education is in fact, "reverse planning" as it is grounded on identifying the end-product capabilities as the first step in curriculum design. This is contrary to the input based model widely used earlier in which the emphasis was on the educational process rather than clearly and unambiguously defining the capabilities of the graduate or specialist. Outcome-based education has been described "as a way of designing, developing, delivering and documenting instruction in terms of its intended goals and outcomes. Exit outcomes are a critical factor in designing the curriculum" [5]. The emphasis of OBE is, therefore, on the outcomes the students need to demonstrate at the end of their professional course or programme rather than the writing of learning objectives conceived by the tutors or curriculum developers [6]. See Figure 1.

\section{The continuum of medical education}

The central mission of medical education is to improve the quality of healthcare delivered by doctors and to achieve this goal, one must align undergraduate medical education to postgraduate training, as well as to future continuing professional development programmes. Thus, for an effective and goal-oriented design it becomes imperative to conduct, first, a proper needs analysis based on future practice requirements and possible challenges that practitioners may encounter. Moreover, it is also necessary to develop non-domain specific skills sets such as communication, leadership and team-skills [7,8].

Developing a surgical curriculum: Situational analysis As discussed earlier, for any medical or health professional curriculum to be effective, it must have a symbiotic relationship with future practice. To educationally prepare a safe surgeon one must not only focus on the training programme for graduates entering into the surgical residency or postgraduate training programmes but also start at the undergraduate medical education. This can be achieved through a proper needs analysis.

A needs analysis is a systematic process of gathering information to identify the current gaps and future needs for the profession [9]. Such information is usually obtained from key stakeholders such as practicing surgeons, professional bodies and licensing authorities, young graduates, trainees and medical students, clinical and preclinical tutors, community leaders and patient advocates, health policy planners, educators and funders This step is critical for curriculum design to develop a context specific graduate surgeon profile to identify training outcomes to build relevant course content and assessment processes [10].

\author{
Developing a surgical curriculum: Identifying end \\ product capabilities
}

\section{Competency framework for undergraduate and} residency (specialty) programme
- Medical knowledge
- Patient care
- Interpersonal and communication skills
- Professionalism
- $\quad$ Practice based learning improvement
- System based practice

Table 1: Overall competency framework for undergraduate and residency training at School of Medicine, National University of Singapore and Residency Programme, National University Health System, Singapore

\section{Competency Framework}

Once the profile of the future surgeon is developed, the next step in curricular design is to develop the overall competency framework for the training. Here the best practice is to have a competency framework which would span both undergraduate and postgraduate education(11).The advantages of having one overall competency framework for the continuum of training from undergraduate to postgraduate are the ease of alignment of teaching-learning and ability to track the trainees in achieving the desired attributes for future practice. A good example of having one overall competency framework in actual operation is the undergraduate and postgraduate learning in Singapore. Both undergraduate medical education and all postgraduate disciplines follow the Accreditation Council for Graduate Medical Education International (ACGME-i) six competencies. This allows different institutions involved in training both undergraduates (UG) and Residents (PG) to align their curricula as well as resources for the training programmes. (See Table 1)

Developing an overall competency framework ensures the learning-training for both UG and PG would also adequately include the non-domain specific areas which are equally important in developing an effective and holistic surgeon. Meng (2008) [12] has studied the importance of developing capabilities in these skills sets for successful future professional practice.

\section{Entrustable Professional Activities (EPA) and Milestones}

In medical education, once the overall competency framework is developed, the next step in course design is to identify the requisite EPAs. An EPA is defined by Olle ten Cate (2005) as "A core unit of professional work that can be identified as a task to be entrusted to a trainee once suf- 
ficient competence has been reached" [13,14]. There are two key exit or graduation points in medical education and training for surgeons. The first is after UG medical education as an Intern Medical Officer (HO) or as a Postgraduate Year 1 (PGY1) and the next exit is as a junior surgeon. The relevant EPAs are identified at these two points and aligned to the overall competency framework [15-17]. The teams involved in curriculum development at UG and PG levels need to identify what are the key professional activities a HO/PGY1 would be able to do without supervision and what are the tasks which need further training in PG years and which trainees could be entrusted with, once sufficient competencies have been achieved. Furthermore, the achievement of each EPA is signposted with key mile- stones or outcomes the medical student or the trainee needs to develop/learn/achieve along the way [15]. The advantage of this model of curriculum development is that it gives clarity to both the student/trainee and the tutor what the student/trainee needs to achieve at a specific point in time of their learning-training, and whether the student/trainee is accomplishing these milestones so that she/he would be granted the entrustment at the designated point of exit. The milestones or outcomes which the student or trainee needs to achieve for each phase of learningtraining will be developed by the relevant tutors in charge of student learning for that particular phase or year. The tutors will carefully align milestones or outcomes to the EPAs and the overall competency framework.

(See Table 2)

\section{Specialty: Surgery}

Topic/core problem: general surgery- abdominal lump

\begin{tabular}{|c|c|c|c|c|c|c|c|c|c|}
\hline \multirow{2}{*}{$\begin{array}{l}\text { Entrustable } \\
\text { Professional } \\
\text { Activities } \\
\text { (EPAs) }\end{array}$} & \multirow[t]{2}{*}{$\begin{array}{c}\text { Outcomes / Year or Phase } \\
\text { specific milestones }\end{array}$} & \multicolumn{6}{|c|}{$\begin{array}{l}\text { Expectations by year of } \\
\text { training (Level of } \\
\text { entrustment/standar d) }\end{array}$} & \multirow{2}{*}{$\begin{array}{l}\text { Co } \\
\text { mp } \\
\text { ete } \\
\text { ncy }\end{array}$} & \multirow[t]{2}{*}{$\begin{array}{l}\text { Types of } \\
\text { assessment }\end{array}$} \\
\hline & & $\begin{array}{l}\mathrm{Y} \\
1 \\
\end{array}$ & $\begin{array}{l}\mathrm{Y} \\
2 \\
\end{array}$ & $\begin{array}{l}\mathrm{Y} \\
3\end{array}$ & $\begin{array}{l}Y \\
4\end{array}$ & $\begin{array}{l}Y \\
5\end{array}$ & $\begin{array}{c}\text { PGY } \\
1 \\
\end{array}$ & & \\
\hline \multirow[t]{4}{*}{$\begin{array}{l}\text { Manage a } \\
\text { patient } \\
\text { presenting } \\
\text { with a lower } \\
\text { abdominal } \\
\text { lump }\end{array}$} & $\begin{array}{l}\text { Apply knowledge of relevant } \\
\text { anatomy, physiology } \& \\
\text { pathophysiology in patient } \\
\text { care (Phase/Year } 1 \\
\text { Outcome) }\end{array}$ & \multirow[t]{4}{*}{1} & \multirow[t]{4}{*}{1} & \multirow[t]{4}{*}{2} & \multirow[t]{4}{*}{3} & \multirow[t]{4}{*}{3} & \multirow[t]{4}{*}{4} & \multirow[t]{4}{*}{$\begin{array}{l}\mathrm{CS} \\
\mathrm{I} \& \\
\mathrm{C} \\
\mathrm{P}\end{array}$} & $\mathrm{MCQ} M \mathbb{M E Q}$ \\
\hline & $\begin{array}{l}\text { Obtain an appropriate history } \\
\text { from the patient (Phase } 2 \\
\text { Outcome) }\end{array}$ & & & & & & & & OSCE \\
\hline & $\begin{array}{l}\text { Perform an age, gender \& } \\
\text { socio-culturally appropriate } \\
\text { exam, identifying major } \\
\text { abnormalities (Phase } 3 \\
\text { Outcome) }\end{array}$ & & & & & & & & $\begin{array}{l}\text { MiniCEx } \\
\text { CbDs }\end{array}$ \\
\hline & $\begin{array}{l}\text { Creates an appropriate initial } \\
\text { care plan, including } \\
\text { diagnostic testing, treatments, } \\
\text { preventive care (Phase } 5 \\
\text { Outcome) }\end{array}$ & & & & & & & & $\begin{array}{l}\text { Practice } \\
\text { Audits }\end{array}$ \\
\hline
\end{tabular}




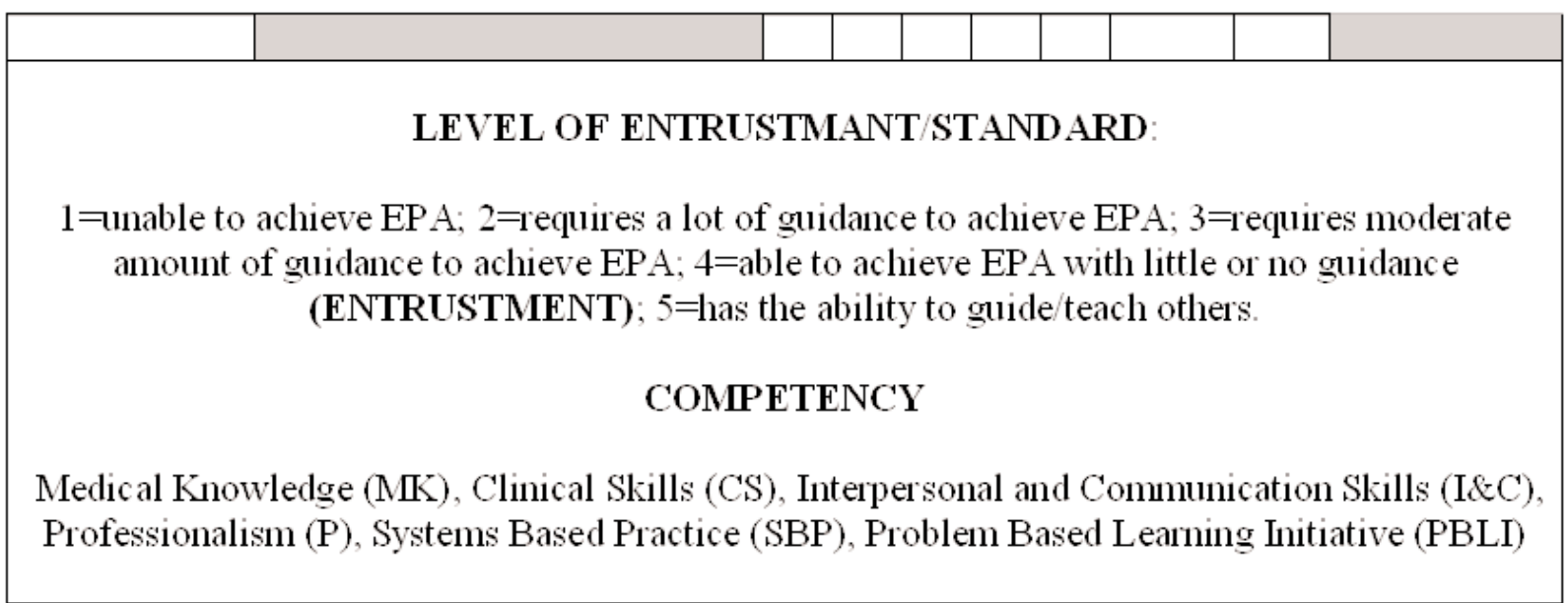

Table 2: An example of a curriculum documentation template linking an UG EPA in surgery with phase or year specific outcomes/milestones, assessment and alignment to the overall competency framework.

\section{Developing a surgical curriculum: content building and delivery - what should be learned and how?}

The next step in curriculum design is to select the relevant content/subject areas that students need to learn in order to achieve the phase or year specific milestones/outcomes. See Figure 1. The content selected should reflect the areas of the competency framework and, hence, the future surgeon profile aligned to the exit EPAs. Each tutor involved in the process will identify the relevant content knowledge, skills sets and attitudinal components necessary for the student/trainee.

Once the content areas are identified and selected, the curriculum designers and tutors (with the assistance of course administrators) need to develop and design appropriate strategies (teaching-learning methods) for the effective delivery of the course content. The decision to use a specific content delivery method should be based on contemporary learning principles. The students and trainees need to be actively engaged in the teaching-learning process, rather than become passive listeners and recipients of content knowledge. The learning should be suited as much as possible to individual learners and contextualised to their future practice environments. Each teaching-learning method should strive to activate learners' prior knowledge regarding the content/subject area and also, facilitate the development of learners' metacognition by providing effective feedback [18-20]. Finally, the process of developing expertise from a novice stage is a stepwise process as described by Dreyfus and Dreyfus. This model is used widely in medical education now as it also closely reflects the continuum of medical education [21,22]. The content and the teaching-learning methods should reflect this important paedagogical aspect [23,24].
As part of an educator's tool kit, there are already many teaching-learning delivery methods (strategies) which can be used. Acquiring knowledge in the cognitive or knowledge domains could involve small group or large group teaching-learning sessions, such as Team Based Learning, Problem Based Learning, Case Based Learning or interactive lectures[25,26]. Similarly for skills based and attitudinal training, initial sessions in the skills labs or simulation based preparation using standardised participants or manikins are recommended. Once sufficient competency has been achieved, one must undertake a supervisory role bedside learning which is the current best practice. This ensures patient safety as well as development of appropriate clinical diagnostic skills [8, 27-29].

Developing a surgical curriculum: student assessment and performance based progression - did they learn?

Alignment of assessment to the EPAs/Outcomes is a critical step in the medical curriculum design process. There is renewed focus currently regarding what type of assessments and how assessments are placed in the training programmes. If designed well, assessments will drive students' learning behaviours which motivate them to learn deeper with understanding and assist them to identify areas of strengths as well as areas for improvement. It is important to use the assessment tools intelligently to drive the student/trainees learning (assessment for learning) as well as to assess whether they have learned what they are required to learn as part of certification or progression (assessment of learning[30-33] .

\section{Assessment for learning}

Most of the current assessment is heavily biased towards ranking purposes and focuses mainly on trying to identify what the student's or trainee's weaknesses are rather than to promote learning and to prepare them for future practice. This has led to the design of assessments out of alignment to the course statements of intent. The Best Evidence Medical Education systematic review by Hossam Hamdy 
and colleagues titled Predictive values of measurements obtained in medical schools and future performance in medical practice found that "existing (assessment) tools do appear to have low to moderate correlation with post-graduate training performance, little is known about their relationship to longer-term practice patterns and outcomes." [34]. To promote learning, as well as to prepare the trainees for future challenges, new modalities of assessment tools such as Workplace Based Assessments (WPBA) are now incorporated widely into the medical curricula. Figure 2 shows the structuring of different assessment tools using the Miller's pyramid [35]. Initial studies show promising results for incorporating more WPBA such as Mini Clinical Evaluation Exercise, Direct Observation of Procedural Skills, Case Based Discussions and Multi Source Feedback. This allows students and trainees immediate feedback on their performance and helps them to improve shortcomings [36,37]. Linking assessment of learning to milestones or Phase/ year specific outcomes allows students and trainees to gauge how well they are developing the necessary skills for the required competencies (See Table 2).

\section{Assessment of learning}

Assessment is also used to appraise whether one has developed sufficient competence in acquiring the required knowledge, skills and attitudes. This is an important step in performance based progression and competency certification for licensing as a doctor or surgeon [30-32]. The critical step is the close alignment of both types of assessment and to ensure the right balance (See Table 2). Consensus between UG and PG trainers and the course developers are important to achieve this equilibrium in getting the process of assessment continuum right (See Figure 2).

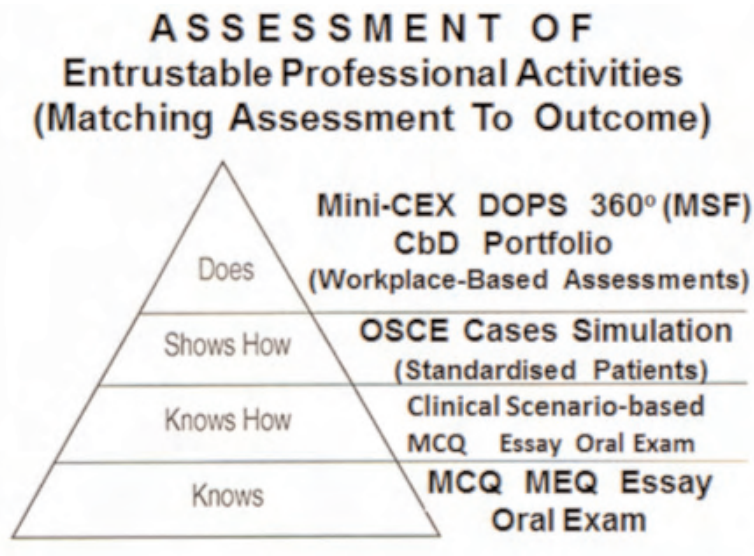

DOPS: Direct Observations of Procedural Skills

CEX: Clinical Examination

CbD: Case based Discussion

MSF: Multi Source Feedback or $36^{\circ}$ Assessment
Developing a surgical curriculum: curriculum evaluation - was the programme impactful?

The final step in curriculum development is to evaluate the programme or course for its effectiveness and impact. There are a few ways of evaluating a programme and the most commonly used is the Kirkpatrick model [38] and Outcome Logic Model [39] .The following section will expand on the four levels of the Kirkpatrick model of evaluation (See Figure 3).

\section{Kirkpatrick model - Four Levels}

\section{LEVEL 1 REACTIONS/PERCEPTIONS}

\section{LEVEL 2 LEARNING}

\section{LEVEL 3 TRANSFER/PERFORMANCE}

\section{LEVEL 4 RESULTS}

Figure 3: Illustrating Kirkpatrick model for programme evaluation

\section{Using Kirkpatrick Four Levels to evaluate the course/programme}

The main purpose of programme evaluation is to apply evidence based on local quality improvement to ensure continuous refinement to the curricular process and to the end product. The process should therefore, encompass the analysis of course delivery (the curricular process) and achievement of course outcomes/EPAs (the end product capability). Evaluation is about collecting information in a systematic manner in order to make a value judgement regarding the course and is different from educational research which is based on a research question and aimed at generating results that could be applied to wide educational settings [40].

\section{Kirkpatrick Model of Evaluation}

Level 1: Evaluates the learners and teachers reactions to the surgery programme. Perceptions of learners and teachers are captured usually by employing feedback questionnaires, interviews or focus group discussions. The choice of the format depends on the level of expertise and resources available to the institutions. Evaluation at this level is commonly seen. However, one important factor to remember is that positive reaction by the student trainees 
and teachers does not guarantee learning but a negative reaction almost certainly reduces its possibility.

Level 2: Evaluates whether the learners have learned what they were required to learn from participating in the course/programme. The usual tools used are pre-test and post-test results and observations before and after the learning interventions to assess whether learners have acquired new knowledge or change in behaviour as a consequence of learning a new set of skills.

Level 3: Evaluates whether transfer has occurred in the learners' behaviour after completing the programme. The main focus of evaluation is to determine whether the learners have acquired and therefore, transferred the knowledge, skills and attitudes (programme outcomes/EPAs) into day to day practice. In most instances, this is the highest practical level of programme evaluation. The greatest challenge is the difficulty to predict when the change in behavior will occur. Thus, Level 3 evaluation requires proper planning based on discussions between curriculum planners, subject experts and tutors involved in content delivery. The usual tools employed at this level are supervisor evaluations, observational tools such as the use of independent observers, incognito patient assessments, practice based video assessments and learner portfolios.

Level 4: Evaluates the impact of the surgery course on the institution, health-care delivery system at national, regional and global level. The major limitation is the difficulty in isolating only the course specific factors which have contributed to the institutional, national or global change. Some of the tools used to evaluate this aspect are audit of patient records, management and prescribing habits, admission/readmission records and national health statistics just to name a few.

\section{Developing a surgical curriculum: challenges and best practices}

Change management

Any change is a difficult process unless properly managed. Bland, Wersal and colleagues (2000) have investigated change management in medical education. The authors reported that the vision of change must be clearly communicated to all the developing internal networks, as well as building relationships with external environments. Other contributing factors to optimise a curricular change process are resource allocation, faculty development to acquire enabling competencies, aligning the reward system and institutional flexibility to accept successes as well as possible disappointments during the change process [41] . The findings clearly point to the need for a welldesigned plan rather than an ad hoc and enthusiasm-driven course design or curriculum reform. Huggan, Samarasekera and colleagues have described how a tradi- tional postgraduate education system could be reformed into a completely new format successfully within a short time frame if the educational leadership responsible for implementing the change follow a clearly defined plan, as well as obtain relevant support by actively engaging both the top leadership as well as the operational leads [11]

It is important to remember that a curriculum reform involves not only a change in the key interdependent educational elements (course content, teaching-learning and assessment strategies) but also a highly sensitive change process subject to human manipulation and persuasion. Strategic nurturing of all stakeholders to develop consensus for the change is, therefore, essential [42].

\section{Continuity from UG to PG training and beyond}

One of the biggest hurdles in medical education is to align the learning-training continuum from UG setting to PG training. Very often the training institutions for UG and PG are different and also the educators involved in the content delivery may not be the same individuals. The authors have earlier discussed the significance of Outcome-Based Education, especially in clearly identifying the end product capabilities through EPAs and Phase/Year specific learning outcomes or milestones. Exit capabilities or a set of EPAs for UG should be developed with inputs from PG programme educational leaders and tutors. This gives the necessary alignment to UG programme and would help in building context specific subject matter so that the HO/PGY1s would be better prepared to enter into PG surgical training programmes. This practice is far superior and more cost effective than retraining new PG surgical trainees in PGY1 or PGY2 to prepare for their future learning-training [43-46].

\section{Selection processes for PG surgical training pro- gramme}

One of the most challenging decisions in medical education is the selection of the right candidate for the programme, mainly because the process needs to be objective, valid, reliable, transparent and fair. However, current processes available for selection of the "right" candidate fall far short of the ideal. Some aspects to consider are the prospective surgical trainee's ability to apply and integrate relevant basic medical sciences, prior involvement in clinical research, interest in the discipline of surgery, ability to demonstrate the integration of cognitive and basic surgical skills learned during UG training [30,47-49]. Furthermore, Panait and colleagues, in reporting their study in the Journal of Surgical Research (2011), maintained that selection criteria for surgical training which incorporate technical proficiency skills are more likely to better discriminate those applicants with an aptitude for a surgical specialty [50]. 


\section{Surgical education and training in an era of reduced working hours}

Many PG accreditation bodies in the US, UK, Europe, Australia and Singapore now require stipulated working hours for surgical and other PG residency training programmes. The number of hours a resident could work and train has been significantly reduced to ensure patient safety and resident welfare. This has led to major reforms in residency training by reducing redundancy and optimising learning opportunities for the resident. Furthermore, relevant and goal driven faculty training, use of technology to enhance surgical skills and deliver content knowledge have been incorporated to PG surgery residency programmes [30, 51-55].

\section{The three levels of curricula \\ - Planned curriculum \\ - Delivered curriculum \\ - Experienced curriculum}

The primary goal of developing a curriculum is to align all three levels of curricula mentioned above. The delivered and experienced curricula may not be the same as the planned curriculum on paper if the planning is inadequate during the operationalizing phase. Other factors which may contribute to this misalignment are inadequate faculty preparation due to poor or substandard faculty development programmes and due also to resourcing issues [3]. Misalignment could also lead to what is termed in medical education - the "hidden curriculum" where student learning is inappropriate and often leads to the development of negative learning constructs acquired from negative role models [56].

\section{Conclusion}

Developing a robust and context specific surgical training continuum spanning both UG and PG training in medical education needs careful planning based on best evidence medical education (BEME) theory and rationale. If properly developed and operationalised, the end-product of a surgical training programme will be equipped to deliver effective safe care to the individual and community s/he is serving in this new millennium.

\section{Acknowledgement}

The authors would like to thank Dr. Deepti Nayak and Mr. Yeo Su Ping from the Medical Education Unit, Yong Loo Lin School of Medicine, National University of Singapore, National University Health System for assisting us in editing and developing the layout of the manuscript.

\section{References}

1. Molly Cooke DMI, Bridget C. O'Brien, Lee S. Shulman Educating Physicians: A Call for Reform of Medical School and Residency.Today's Practice,
Yesterday's Legacy, Tomorrow's Challenges. . San Francisco,CA: Jossey-Bass; 2010 June.

2. Bligh. Taking Stock. Medical education. 2000;34:41617.

3. Prideaux D. ABC of learning and teaching in medicine. Curriculum design. BMJ. 2003;326(7383):268-70. Epub 2003/02/01.

4. Harden JR. AMEE Guide No. 14: Outcome-based education: Part 5-From competency to meta-competency: a model for the specification of learning outcomes. Medical teacher. 1999;21(6):546-52. Epub 1999/01/01.

5. Spady W. Organising for results: The basis for authentic restructuring and reform. Educational Leadership. 1988;46(2):4-7.

6. Harden RM. Outcome-Based Education: the future is today. Medical teacher. 2007;29(7):625-9. Epub 2008/02/01.

7. Barrow M, McKimm, J. \& Samarasekera, D.D. Strategies for planning and designing medical curricula and clinical teaching. South East Asian Journal of Medical Education. 2010;4:2-8.

8. Hirsh DA, Ogur B, Thibault GE, Cox M. "Continuity" as an organizing principle for clinical education reform. The New England journal of medicine. 2007;356(8):858-66. Epub 2007/02/23.

9. Brown J. Training needs assessment: A must for developing an effective training programme. Public Personnel Management. 2002;31(4).

10. Bleakley A. The curriculum is dead! Long live the curriculum! Designing an undergraduate medicine and surgery curriculum for the future. Medical teacher. 2012;34(7):543-7. Epub 2012/05/29.

11. Huggan PJ, Samarasekara DD, Archuleta S, Khoo SM, Sim JH, Sin CS, et al. The successful, rapid transition to a new model of graduate medical education in Singapore. Academic medicine : journal of the Association of American Medical Colleges. 2012;87(9):1268-73. Epub 2012/07/28.

12. Meng C. Discipline-specific and academic competencies of the higher educated:their value in the labour market and their acquisition in education. Maastricht University2006.

13. Frank JR, Snell LS, Cate OT, Holmboe ES, Carraccio C, Swing SR, et al. Competency-based medical education: theory to practice. Medical teacher. 2010;32(8):638-45. Epub 2010/07/29. 
14.ten Cate O. Entrustability of professional activities and competency-based training. Medical education. 2005;39(12):1176-7. Epub 2005/11/30.

15. Boyce P, Spratt C, Davies M, McEvoy P. Using entrustable professional activities to guide curriculum development in psychiatry training. BMC medical education. 2011;11:96. Epub 2011/11/25.

16. Mulder H, Ten Cate O, Daalder R, Berkvens J. Building a competency-based workplace curriculum around entrustable professional activities: The case of physician assistant training. Medical teacher. 2010;32(10):e453-9. Epub 2010/09/22.

17.ten Cate O, Scheele F. Competency-based postgraduate training: can we bridge the gap between theory and clinical practice? Academic medicine : journal of the Association of American Medical Colleges. 2007;82(6):542-7. Epub 2007/05/26.

18. Applebee M. Curriculum as conversation: Transforming traditions of teaching and learning. Chicago, IL: University of Chicago Press; 1996. .

19. Cooke M ID, O'Brien BC. . Educating physicians: A call for reform of medical school and residency. . San Francisco: Jossey-Bass; 2010.

20.Genn JM. AMEE Medical Education Guide No. 23 (Part 1): Curriculum, environment, climate, quality and change in medical education-a unifying perspective. Medical teacher. 2001;23(4):337-44. Epub 2002/07/06.

21. Dreyfus S DH. A five stage model of the mental activities involved in directed skill acquisition. California University Berkeley Operations Research Center 1980.

22. Pena A. The Dreyfus model of clinical problem-solving skills acquisition: a critical perspective. Medical education online. 2010;15. Epub 2010/06/22.

23. Benner P. From novice to expert: excellence and power in clinical nursing practice, commemorative edition. Upper Saddle River, NJ: Prentice-Hall; 2001.

24. Boshuizen HPAS, H.G Clinical reasoning in the health professions. 2 ed: Oxford: Butterworth-Heinemann; 2000.

25. Dujeepa D. Samarasekera IMK. Hub format an innovative design for effective small group learning. South East Asian Journal of Medical Education. 2011;5(1).

26. Prober CG, Heath C. Lecture halls without lectures--a proposal for medical education. The New England journal of medicine. 2012;366(18):1657-9. Epub 2012/05/04.

27. Bowen JL. Educational strategies to promote clinical diagnostic reasoning. The New England journal of medicine. 2006;355(21):2217-25. Epub 2006/11/25.

28. Eva KW. What every teacher needs to know about clinical reasoning. Medical education. 2005;39(1):98-106. Epub 2004/12/23.

29. Ramani S. Twelve tips to improve bedside teaching. Medical teacher. 2003;25(2):112-5. Epub 2003/05/15.

30. Rational reform to medical education in India. Lancet. 2011;377(9773):1212. Epub 2011/04/19.

31.Epstein RM. Assessment in medical education. The New England journal of medicine. 2007;356(4):38796. Epub 2007/01/26.

32. Epstein RM, Hundert EM. Defining and assessing professional competence. JAMA : the journal of the American Medical Association. 2002;287(2):226-35. Epub 2002/01/12.

33. Gardner J. Assessment and Learning. London: sage publications 2006.

34. Hamdy H, Prasad K, Anderson MB, Scherpbier A, Williams R, Zwierstra R, et al. BEME systematic review: predictive values of measurements obtained in medical schools and future performance in medical practice. Medical teacher. 2006;28(2):103-16. Epub 2006/05/19.

35. Miller GE. The assessment of clinical skills/competence/performance. Academic medicine : journal of the Association of American Medical Colleges. 1990;65(9 Suppl):S63-7. Epub 1990/09/01.

36. Govaerts MJ, van der Vleuten CP, Schuwirth LW, Muijtjens AM. Broadening perspectives on clinical performance assessment: rethinking the nature of intraining assessment. Advances in health sciences education : theory and practice. 2007;12(2):239-60. Epub 2006/11/11.

37. McGill DA, van der Vleuten CP, Clarke MJ. Supervisor assessment of clinical and professional competence of medical trainees: a reliability study using workplace data and a focused analytical literature review. Advances in health sciences education : theory and practice. 2011;16(3):405-25. Epub 2011/05/25.

38. Kirkpatrick DLKaJD. Implementing the Four Levels: A Practical Guide for Effective Evaluation of Training Programmes. San Francisco: Berrett-Koehler Publishers; 2007.

39. Millar A, R.S. Simeone, and J.T. Carnevale. Logic models: a systems tool for performance management. Evaluation and Programme Planning. 2001;24:73-81. 
40.Levin-Rozalis M. Evaluation And Research: Differences And Similarities. The Canadian Journal of Programme Evaluation. 2003;18(2):1-31.

41. Bland CJ, Starnaman S, Wersal L, MooreheadRosenberg L, Zonia S, Henry R. Curricular change in medical schools: how to succeed. Academic medicine : journal of the Association of American Medical Colleges. 2000;75(6):575-94. Epub 2000/06/30.

42. Gwee MC. Medical and health care professional education in the 21st century: institutional, national and global perspectives. Medical education. 2011;45(1):25-8. Epub 2010/12/31.

43. Boehler ML, Rogers DA, Schwind CJ, Fortune J, Ketchum J, Dunnington G. A senior elective designed to prepare medical students for surgical residency. American journal of surgery. 2004;187(6):695-7. Epub 2004/06/12.

44. Brunt LM, Halpin VJ, Klingensmith ME, Tiemann D, Matthews BD, Spitler JA, et al. Accelerated skills preparation and assessment for senior medical students entering surgical internship. Journal of the American College of Surgeons. 2008;206(5):897-904; discussion -7. Epub 2008/05/13.

45. Naylor RA, Hollett LA, Castellvi A, Valentine RJ, Scott DJ. Preparing medical students to enter surgery residencies. American journal of surgery. 2010;199(1):105-9. Epub 2010/01/28.

46. Peyre SE, Peyre CG, Sullivan ME, Towfigh S. A surgical skills elective can improve student confidence prior to internship. The Journal of surgical research. 2006;133(1):11-5. Epub 2006/04/04.

47. Gallagher AG, Neary P, Gillen P, Lane B, Whelan A, Tanner WA, et al. Novel method for assessment and selection of trainees for higher surgical training in general surgery. ANZ journal of surgery. 2008;78(4):28290. Epub 2008/03/28.

48. Melendez MM, Xu X, Sexton TR, Shapiro MJ, Mohan EP. The importance of basic science and clinical research as a selection criterion for general surgery residency programmes. Journal of surgical education. 2008;65(2):151-4. Epub 2008/04/29.
49. Schult M, Vowinkel T, Senninger N. [How are beginning students in surgery selected? Results of a survey of German consultant surgeons]. Der Chirurg; Zeitschrift fur alle Gebiete der operativen Medizen. 2001;72(5):621-9. Epub 2001/06/01. Wie werden Berufsanfanger in der Chirurgie ausgewahlt? Ergebnisse einer Umfrage unter deutschen Chefarzten.

50. Panait L, Larios JM, Brenes RA, Fancher TT, Ajemian MS, Dudrick SJ, et al. Surgical skills assessment of applicants to general surgery residency. The Journal of surgical research. 2011;170(2):189-94. Epub 2011/05/27.

51. Benes V. The European Working Time Directive and the effects on training of surgical specialists (doctors in training): a position paper of the surgical disciplines of the countries of the EU. Acta neurochirurgica. 2006;148(11):1227-33. Epub 2006/11/15.

52. Collins JP. International consensus statement on surgical education and training in an era of reduced working hours. The surgeon : journal of the Royal Colleges of Surgeons of Edinburgh and Ireland. 2011;9 Suppl 1:S3-5. Epub 2011/10/05.

53. Gough IR. The impact of reduced working hours on surgical training in Australia and New Zealand. The surgeon : journal of the Royal Colleges of Surgeons of Edinburgh and Ireland. 2011;9 Suppl 1:S8-9. Epub 2011/10/05.

54. Sakorafas GH, Tsiotos GG. New legislative regulations, problems, and future perspectives, with a particular emphasis on surgical education. Journal of postgraduate medicine. 2004;50(4):274-7. Epub 2004/12/30.

55. Traynor O. Surgical training in an era of reduced working hours. The surgeon : journal of the Royal Colleges of Surgeons of Edinburgh and Ireland. 2011;9 Suppl 1:S1-2. Epub 2011/10/05.

56. Hafferty FW, Franks R. The hidden curriculum, ethics teaching, and the structure of medical education. Academic medicine : journal of the Association of American Medical Colleges. 1994;69(11):861-71. Epub 1994/11/01. 